\title{
SEEING ISN'T BELIEVING: UNDERSTANDING DIVERSITY IN THE TIMING OF STRATEGIC RESPONSE*
}

\author{
Pamela S. BARR \\ Emory University
}

ANNE S. HuFF

Cranfield School of Business and University of Colorado

\section{ABSTRACT}

There is general consensus in the strategy literature that successful firms alter strategy to address changes in their environments and enact more favourable conditions. Studies of organizational change suggest that this adjustment is not always made in a timely manner. Different beliefs about cause and effect have been established as a plausible explanation for differential responses to environmental change. This exploratory study of six pharmaceutical firms suggests more specifically that multiple concepts associated with environmental changes must be directly linked to organizational performance before new strategies are initiated. The results emphasize the importance of stress as a precursor to strategic response and have implications for the way we conceptualize 'response' when referring to significant changes in strategy.

\section{INTRODUCTION}

One fundamental normative prescription is consistent throughout almost all of the strategy literature: firm strategists must continually monitor the environment and make strategic decisions that keep firm strengths aligned with new opportunities and threats in the environment (Andrews, 1987; Ginsberg, 1988; Miles and Snow, 1978; Mintzberg, 1978; Porter, 1980; Quinn, 1980; Hofer and Schendel, 1978). Research has demonstrated that firms changing strategy in response to changes in the environment outperform those that maintain current strategies in the face of new circumstances (Haveman, 1992; Smith and Grimm, 1987). Further, the evidence suggests that firms failing to adjust in a timely fashion may enter a downward spiral from which they do not escape (Cameron et al., 1988; Hambrick and D'Aveni, 1988).

Despite the obvious benefits of adjusting strategy to meet the changing demands of the environment, a number of recent articles point out that it is often difficult or impossible for firms to change strategy (Miles and Snow, 1978;

Address for reprints: Pamela S. Barr, Goizueta Business School, Emory University, Atlanta, Georgia 30322, USA 
Miller and Friesen, 1984; Oster, 1982; Schwenk and Tang, 1989; Tushman and Romanelli, 1985; Zajac and Shortell, 1989). For example, limitations on strategic change have been attributed to established commitments (Monteverde and Teece, 1982; Thompson, 1967), the existence of buffering organizational slack (Chakravarthy, 1982; Cyert and March, 1963), and the development of standard operating procedures (Hannan and Freeman, 1984). It is therefore not surprising to note that firms in profoundly changing environments and/or firms with significantly deteriorating performance vary significantly in the timing of their attempts to alter strategy (Ginsberg and Buchholtz, 1990; Haveman, 1992; Miles and Snow, 1978; Miles, 1982; Smith and Grimm, 1987).

The question that interests us is why some firms are able to overcome the forces of inertia more quickly than others, and we begin with the assumption that the timing of strategic adjustment is significantly affected by top managers' interpretation of the environment's impact on the firm. Researchers have proposed that environmental interpretation affects action through such precursors to action as problem definition (Lyles and Mitroff, 1980; Mintzberg et al., 1976) and strategic issue diagnosis (Dutton and Duncan, 1987; Dutton et al., 1983). Dutton and Duncan specifically suggest that '... a major reason organizations respond differently to changes in the environment involves how strategic issues are triggered and interpreted by decision makers' (p. 279). We follow this line of reasoning, and discover that perceived connections between the environment and the firm explain differences in the timing of strategic response.

The paper addresses three issues in sequence. First, it pulls together several theoretic arguments needed to address the timing issue. Second, it reviews the methodological issues that have to be addressed before the details of timing can be explored. It then presents empirical evidence of interpretive distinctions among six pharmaceutical companies that differed by up to five years in their response to new regulatory change.

\section{THE LINK BETWEEN MANAGERIAL INTERPRETATION AND STRATEGIC CHANGE}

The effect of interpretation on firm adaptation to changes in the environment has enjoyed increased empirical attention since Weick's (1979) statement that the environment is not an objective 'thing' to be known, but rather the product of interpretation and action. Interpretation has been found to affect the response of hospitals to a doctors' strike (Meyer, 1982), the revision of basic philosophical and theological principles by a religious order (Bartunek, 1984), university reaction to a drop in the number of available 18 year olds (Milliken, 1990), the passage of new patient care regulations by mental hospitals (Scheid-Cook, 1992), and response to crisis in the Finnish banking industry (Myllys, 1994).

These five studies share certain similarities. Each looks at firm response to a significant event in the environment, an event that was expected to affect the strategic behaviour of all firms in the sample. Despite the similarity of the organizations studied, however, the response of each to the external changes varied significantly (with the exception of Bartunek's study of a single organization). Each author concludes that variability in the content or certainty of strategic response could be attributed to variations in interpretation about the environment. 
These interesting studies also raise issues that are problematic for relating interpretation and change. First, the studies vary in their explicit recognition of the cognitive processes involved in interpreting new events. Second, each (with the exception of Myllys, 1994) does not explicitly address level of analysis issues that are automatically raised when one applies an individual level concept, such as interpretation, to organization level behaviour. Third, they do not adequately account for why some organizations are more quickly impressed by environmental change than others. Further understanding requires that these issues be brought together in the same theoretic account. In the following discussion, we address each of these issues individually and then bring them together in a single model of interpretation and strategic change that we then use to guide our empirical study.

\section{Schematic Frameworks as the Basis for Interpreting the Environment}

The processes of noticing and interpreting stimuli have been linked by cognitive scientists to schemas the individual has already formulated (Fiske and Taylor, 1991; Neisser, 1967). 'Schemas' and other related concepts (frames, mental models) identify the simplified and abstracted representations individuals use to make sense of and act within their environments (Gioia and Sims, 1986; Kelly, 1955; Minsky, 1975; Rumelhart, 1980; Walsh, 1995; Weick and Bougon, 1986). A schema is a set of interrelated, largely unquestioned assumptions that highlights certain characteristics of new stimuli and establishes the grounds for categorizing them as similar to or different from those encountered before (Fiske and Taylor, 1991). Nisbett and Ross (1980), for example, found that when questioned, individuals will recall elements of a stimulus that are most salient in their mental models, while ignoring other characteristics that are not central to that general frame. Researchers interested in organizational contexts also suggest that individuals pay greater attention to occurrences that support their existing assumptions (Hedberg et al., 1976) and then act to confirm these beliefs (Kiessler and Sproull, 1982). Stimuli that can't be placed within existing frameworks may generate new schema, but this is a time-consuming and uncertain process. Starbuck and Milliken (1988) note that the belief systems held by managers regarding what is important in the environment are more likely to push information that might indicate the need for new schemata to the background of attention where they are unlikely to be acted upon.

The basic concept of schema has been very useful to researchers concerned with the complex, confusing and ambiguous settings that characterize most organizations (Allison, 1971; March and Simon, 1958). Schematic frameworks have been proposed as critical simplifying and sensemaking mechanisms that allow the individual to make sense of stimuli-rich contexts and act within them (Daft and Weick, 1984; Kiesler and Sproull, 1982). The proposition that managers hold schematic frameworks related to their firms has been empirically illustrated by several authors. Extensive work by Colin Eden and colleagues (e.g. Eden et al., 1979, 1983), for example, uses cognitive mapping techniques to uncover schematic frameworks of several different organizational concepts held by managers at different organizations. Importantly, this work highlights the fact that interpretations or beliefs about the environment are highly subjective and often idiosyncratic. It is these idiosyncrasies, or differences in schematic frame- 
works that we suggest accounts for much of the diversity in timing of response to significant environmental changes. Before such a proposal can be investigated, however, it is necessary to move this individual-based concept to the level of the organization.

\section{Beyond the Individual: Shared Schematic Frameworks as the Basis for Co-ordinated Activity}

Researchers interested in linking firm response to the environment to cognitive processes typically treat 'the firm' as if it were a unitary actor noticing changes in its situation, and thus draw directly upon the kind of cognitive arguments just cited. This practical simplification is problematic, of course, because cognition is an attribute of individuals. One way out of the conundrum is to consider the absolute necessity of common schematic frameworks for achieving co-ordinated action. Several interesting lines of inquiry outside of the management field emphasize the necessity of shared belief and interpretation as the basis for social behaviour. These streams of research also suggest how commonalities that support collective activity come about. For example, an interest in the source of scientific discovery led Kuhn (1970) to define scientific communities on the basis of a shared paradigmatic framework. This work emphasizes the importance of shared understanding for defining the most important scientific work to be pursued. Kuhn points to professional training, established procedures, compelling experiments, and formal and informal interaction among scientists as the means of establishing and solidifying common assumptions.

An analogous line of reasoning in political science investigates the development of 'epistemic communities' (Haas, 1992). This work is driven by an interest in understanding how new policies (e.g. monetary reform or environmental protection) are developed by government agencies. Peter Haas suggests that such groups have:

(1) a shared set of normative and principled beliefs, that provide a valuebased rationale for the social action of community members;

(2) shared causal beliefs, that are derived from their analysis of practices leading or contributing to a central set of problems in their domain and which then serve as the basis for elucidating the multiple linkages between possible policy actions and desired outcomes;

(3) shared notions of validity - that is, intersubjective, internally defined criteria for weighing and validating knowledge in the domain of their expertise; and

(4) a common policy enterprise - that is, a set of common practices associated with a set of problems to which their professional competence is directed, presumably out of the conviction that human welfare will be enhanced as a consequence. (Haas, 1992, p. 3)

These and other works are convincing testimony for the necessity of shared understanding to accomplish co-ordinated social tasks. The possibility of co-ordination is what leads to social organization in the first place (Barnard, 1938) and there are strong philosophical arguments that extensive commonalities are necessary for any kind of social exchange (Gilbert, 1989; Kelly, 1955). The consequence for the organization is that 'organizational cognition cannot be seen as 
an individualised act, but rather as an "inseparable aspect" (Lave and Wenger, 1991) of the continual, local negotiation and re-negotiation of meanings between actors' (Wood, 1996, p. 1). Thus, organization cognition is a reciprocal concept, in which the individual's interpretation is shaped by the organization and other social contexts, but that cognition is simultaneously creating context (Weick, 1979). There is room for individual differences, but patterns emerge from the whole (Allard Poesi, 1994; Ehlinger, 1994; Fiol, 1994; Stjernberg and Ullstad, 1994).

The underlying assumption of this paper is that organizations, and especially the top management team of organizations, must be 'epistemic communities' of some strength in order to be viable economic units. While individuals continue to have unique beliefs and interpretations, they share many beliefs and understanding with others (Bougon et al., 1977; Hodgkinson and Johnson, 1994). To the extent that beliefs are shared by key actors, the resulting shared schematic frameworks simplify a complex world and provide the basis for co-ordinated activity. Similar structures have been labelled 'shared understanding' (March, 1991), 'cognitive consensuality' (Gioia and Sims, 1986), 'dominant logic' (Prahalad and Bettis, 1986), or shared 'strategic frames' (Huff, 1982) within the organization.

In sum, the cognitive psychology literature suggests that the processes of noticing and interpreting stimuli are directed by cognitive structures called schema. We extend this concept to the organizational level by recognizing the necessity of some level of shared understanding to conduct co-ordinated activity. We term these shared belief systems 'shared schematic frameworks'. In the following section we address the issue of why some firms appear to be more quickly impressed by environmental change by introducing the concepts of stress and inertia.

\section{Stress Opposing Inertia as the Explanation for Timing Differences}

Anomalous stimuli that capture attention but cannot easily be interpreted or responded to in terms of past experience are stressful. At the individual level, new life experiences (marriage, job change, divorce, etc.) have long been recognized as stimuli (Holmes and Rahe, 1967) that are likely to call into question the validity or usefulness of past schema. The range of positive and/or negative emotion attached to such events raises their salience and helps trigger new understanding. On the other hand, schematic frameworks are remarkably resilient. Experiments by Ross and his associates (Anderson et al., 1980; Ross et al., 1975), for example, show that people can persist in explanations even when shown that the evidence they relied on to form those explanations is false.

We believe such accounts of individual cognitive processes are consistent with theoretical assessments of stress and inertia at the organization level (Bigelow, 1982; Ginsberg, 1988; Huff et al., 1992; Olivia et al., 1988; Tushman and Romanelli, 1985). Recent work has emphasized the many factors that help maintain organization activity in the face of environmental change. The general argument is that many impediments to change are a result of deliberate attempts to establish relationships and develop structures and routines that institutionalize beneficial ways of acting (Nelson and Winter, 1982; Selznick, 1957). The more successful these past adaptations have been, the less likely significant departure 
from current ways of acting becomes (Dimaggio and Powell, 1983; Ginsberg and Buchholtz, 1990; Powell and Dimaggio, 1991). In addition to affecting organizational activities, these organizational and institutional forces of inertia are likely to affect the processes of noticing and interpretation (Meyer, 1982; Milliken, 1990). For example, external institutional norms may blind managers to the need to change by emphasizing conformity to a certain set of accepted interpretations, and structural configurations (Hannan and Freeman, 1984) can exacerbate lack of managerial attention by limiting and biasing available information (Starbuck and Milliken, 1988).

In addition to inertial forces developed to maintain status quo, there exist forces for change that serve as organizational corollaries to individual-based concepts of stress. As discussed above, individual stress results from stimuli that cannot easily be addressed with past schema and behaviours. At an organization level, stress follows from stimuli that is interpreted as challenging the appropriateness of current actions and procedures. For example, new circumstances (innovation, government actions, competitive moves, changing leadership, etc.) weaken the 'fit' between an organization and its environment and thus set the stage for calling current structures and routines into question (Andrews, 1987). While stress can arise from direct performance downturns (an indicator that current structures/routines are inappropriate), anticipated circumstances or new achievements by competitors can also be perceived as stressful. These examples of likely stressful events are taken from the strategy literature as examples of stimuli likely to result in a questioning of the appropriateness of current activities, structures and routines. It is important to emphasize, however, that stress is an interpretive construct; any given event or situation may be interpreted in some organizations as stressful, and either overlooked or noticed but not perceived as stressful in others. It is this difference in interpretation that is the focus of attention in our empirical study, and that we propose is at least partially responsible for diversity in the timing of response to environmental change.

In relatively straightforward models, strategic change becomes more and more probable as the stress level (pressure for change) resulting from various stimuli exceeds the current level of inertia (pressure to maintain the status quo) (Huff et al., 1992; Olivia et al., 1988). Of course, both individuals and firms demonstrate the homeostatic capacity to adjust; that is, they are able to mediate stressful events by making changes compatible with existing commitments and schematic frameworks. At this level of inertia, this capacity not only becomes a part of existing procedures, it 'trains' individual managers to be more flexible and adaptive in their interpretations. Adaptive capabilities thus can reduce the impact of many stressful events, but they do not address the firm's vulnerability to events that fall outside of previous experience. Over time, the stress associated with noticed events that cannot be adequately responded to with current activities and procedures exceeds the ability to adjust and significant change is required.

To this point in the paper we have discussed several issues related to taking an interpretation-based view to the timing of strategic change. In the following section, we combine the concepts of shared schematic frameworks and stress and inertia into a single model of strategic change.

(C) Blackwell Publishers Ltd 1997 


\section{A Model of Strategic Change}

Figure 1 provides a general model for understanding the timing of strategic change that incorporates work on stress and inertia with ideas of schema-based interpretive processes. Organizations are assumed to have various formal and informal mechanisms in place to scan their environments. These mechanisms are more or less sensitive to bits of information that might be used to reconsider firm wellbeing. Failure to notice potentially anomalous stimuli results in continued routine scanning. Even if an anomaly producing event is given attention, it must be interpreted or given meaning (Daft and Weick, 1984). Any given event is likely to be imbued with many types of meaning. Of particular relevance to the idea of stress/inertia and strategic change is interpretation of the likely impact (if any) of the event on the firm. Such an interpretation may result in one of two basic outcomes. First, the stimuli may collectively be interpreted as not having a significant impact on the firm. In this case current routines/procedures are not questioned and, thus, the event is not considered stressful. The level of organizational stress is not increased and scanning continues, although future events (or input from other scanning mechanisms) may result in a reinterpretation at a later time.

When an event is interpreted as having an impact on the firm, the pressure to make some change in activity will increase. At this point, a second determination

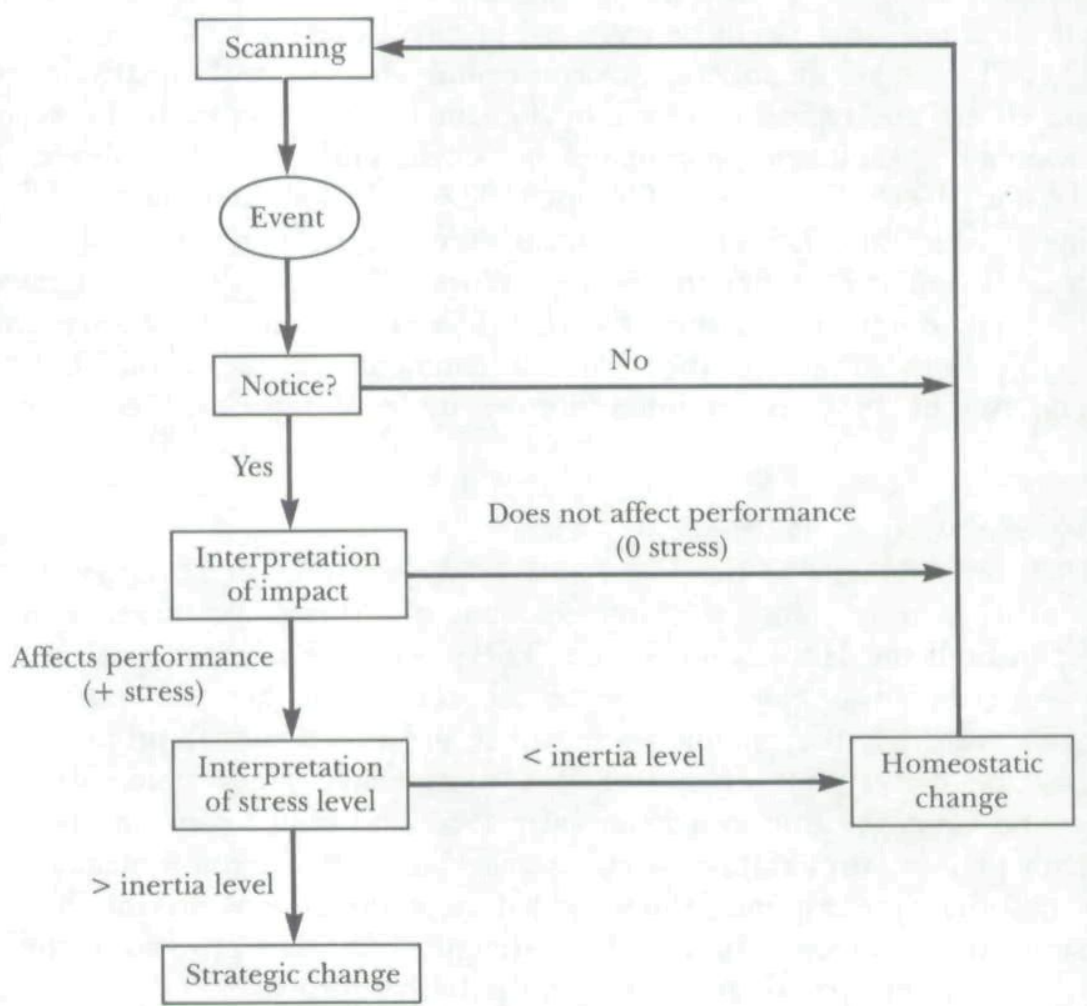

Figure 1. An interpretive model of the strategic change process 
must be made: Is the pressure to change (level of stress) greater than the pressure to maintain the status quo (level of inertia)? If stress is less than inertia, it is probable that discomfort will be addressed through homeostatic adjustments in current strategy. However, as stress exceeds inertia, strategic change is more and more likely to occur.

We used this model as an organizing device in designing an empirical study of timing issues. Linking interpretation to action required solving a number of methodological issues, which will be discussed before returning to the model and our analysis.

\section{STUDY DESIGN}

To assess the relative capacity of firms as 'epistemic communities' to recognize and respond to stimuli potentially indicating a need for a change, we needed to identify a relatively homogeneous set of firms and isolate a strong, unconfounded change in the competitive arena shared by these firms. Data had to be available from the time period in which the event took place, and similar data had to be available for all companies studied. Further, the firms had to be homogeneous enough to be expected to be similarly affected by the environmental change. In addition to these questions of study definition, we needed to establish methods for separately identifying strategic actions and the shared schematic framework or 'strategic frame' that might be expected to direct these activities.

The challenges of identifying environmental changes with relatively homogeneous effects are typically solved by looking at key events in the relatively small number of industries dominated by single business firms (Meyer, 1982; Scheid-Cook, 1992; Smith and Grimm, 1987). We followed this tradition by choosing to study the US pharmaceutical industry. A long period of sustained growth and profitability after the Second World War is evidence of a relatively stress free environment. On the other hand, it is a regulated industry and we were particularly drawn to the 1962 amendments to the Food, Drug and Cosmetic Act of 1938 as an interesting example of significant environmental change.

\section{The Exogenous Shock of 1962 Regulatory Change}

The 1962 amendments to the Food and Drug Act were preceded by years of government hearings and the introduction of several proposed regulatory changes in both the House and Senate. The powerful Pharmaceutical Manufacturers Association was able to influence the content of these amendments and many observers felt they might even defeat the congressional proposals being made in the early 1960s. However, the unexpected Thalidomide disaster in Europe and Canada came to light in early 1962 and public concern about birth defects caused by prescription sleeping pills (and by extension negative sideeffects of other prescription drugs) added new dimensions to the bill being considered in Congress, considerably strengthening the provisions the drug companies had anticipated, and hastened the bill's approval.

The bill contained many provisions, but its major impact was to add several new phases to the drug approval process. The time the Food and Drug Adminis- 
tration (FDA) had to approve a new drug was doubled, with automatic extensions granted to the FDA if the deadline was not met. The FDA was also given the power to withdraw without notice approval from existing drugs if they were found to be unsafe, lacked 'substantial' evidence of effectiveness (evidence of effectiveness was a new requirement in itself), or contained misstated applications. The 17-year legislated life of a drug patent begins at the time the patent is awarded. To protect prospective new drugs from competition, patents commonly are applied for at the time of discovery and prior to testing. The new, more stringent testing requirements resulting from the amendments thus increased the time and expense associated with introducing a new drug and decreased the time available for profiting from patent protection. In fact, the time elapsing from FDA processing time from submission of a New Drug Application to approval increased from 17 months in 1962 to 44 months by 1969 (Temin, 1980), significantly reducing the effective life of the patent.

Several subsequent trends in the industry have been attributed to these changes in the environment. First, there was a significant decline in the number of new drugs introduced in the United States. Between 1950 and 1961, 564 new chemical entities (NCEs), the basis of the FDA approval and patent protection process, were introduced. In the next eight years only 159 went through the system. While a portion of this decrease is due to a 'knowledge plateau', comparative studies of new drug introductions in the USA and UK suggest the amendments also contributed significantly to the decline in new drug introductions (Grabowski et al., 1978; Wardell, 1971).

Second, US pharmaceutical manufacturers became increasingly active overseas. Foreign sales as a percent of total for all US manufacturers increased steadily during the 1960s (Temin, 1980), and US firms increased their investments in overseas activities. For example, the percentage of NCEs first studied and tested in the USA by US firms decreased from 100 per cent at the time the amendments were enacted, to less than 80 per cent by 1970 , and 50 per cent by 1974 (Lasagna and Wardell, 1975).

A third major trend in the industry following enactment of the 1962 amendments was growth through diversification. Most of this activity occurred through acquisitions, both inside and outside the pharmaceutical industry. Of particular significance, US pharmaceutical companies diversified into non-prescription medicines, consumer products such as cosmetics and sundries, and medical equipment and diagnostic aids. Cool (1985) attributes these moves to the pharmaceutical companies' ability to transfer technical knowledge and take advantage of established distribution channels, as well as the hefty profit margins and growth rates available in these markets.

To summarize, the 1962 changes in FDA regulation are seen by analysts as leading to significant changes in the industry, including significant increase in the time and expense associated with bringing a new product to market and a shorter effective patent life. These changes in the environment were reflected in strategic change across the industry, including an increase in overseas expansion and diversification into related businesses. Our questions were: (1) Could we identify significant changes in the timing of such responses to the 1962 legislation? (2) Could these changes be explained in terms of the theoretic ideas summarized in figure 1 ? 


\section{Sample Selection}

Selection of a homogeneous sample for the study was based on four criteria. First, since the stimulus event was significant change in US regulation, we decided candidate firms had to be US-owned, with over 50 per cent of their business conducted in the USA at the start of the study period. Second, all firms in the sample had to have significant commitment (which we defined as over 50 per cent of US sales) to pharmaceutical manufacturing in 1962. Third, all sample firms were required to have at least ten years of history in the pharmaceutical industry prior to the beginning of the study period, to assure the formation of relatively well-developed schemata, which at the organizational level we call 'strategic frames', prior to the change in legislation. Sample firms were also required to be financially healthy at the time of the regulatory change, to avoid confounding changes in strategic frames due to regulatory change with responses to other performance concerns. Our criterion was that changes in profitability do not differ significantly from the experience of the industry as a whole; it was not necessary to be more specific, since financial performance in the study period was not a discounting factor for any of the firms considered. Finally, sufficient financial and textual data had to be available for analysis.

Due to the extensive coding requirements of the cause mapping methodology described below, which we use to identify the strategic frames of each firm over a minimum of seven years, the sample size had to be restricted to a relatively small number of firms. For that reason, the sample was drawn from Forbes' 1962 list of the top ten US pharmaceutical companies. Of those ten, six manufacturers met the four criteria and thus make up the final study sample. These firms are: Abbott Laboratories (Abbott), Merck and Company (Merck), Parke, Davis and Company (Parke-Davis), Smith Kline and French (SKF), Charles Pfizer (Pfizer), and Schering. Once the sample was identified, the next steps were to identify the points in time in which significant changes in strategic action occurred in each firm during the period of interest and to identify the strategic frames of each firm for each year during the same time period. We then used the outcomes of both processes to categorize firms as fast or slow responders and to link the content of strategic frames to the timing of strategic change.

\section{Points of Change in Strategic Action}

Two preliminary analyses were required before the core questions of the study could be addressed. The first involved identifying the timing of strategic change in each sample firm. Following the definition of strategy proposed by Mintzberg and Waters (1982), change in strategy was defined as a significant break in the pattern of resource allocations made by the firm. Four variables associated with industry trends following the 1962 amendments were selected as important indicators of potential strategic change that could be tied to the effects of the amendments: percentage of foreign assets to total assets, research and development (R\&D) expenditures as a percentage of sales, selling expense as a percentage of sales, and liquid to total assets. ${ }^{[1]}$ Percentage of foreign assets to total assets was assumed to reflect directly strategic orientation toward geographic expansion. $R \& D$ as a percentage of sales was used as an indication of commitment to the development of new ethical pharmaceuticals: an increase in this measure is a likely indicator of increased investment due to the new testing requirements, a 
more diversified focus might be reflected in a decline in $R \& D$ as a percentage of total sales. Selling expense as a percentage of sales is also a measure of product emphasis; the marketing of pharmaceuticals required sales visits to physicians that were typically more expensive than marketing over-the-counter remedies or other consumer products. Lastly, liquid to total assets reflects significant changes in capital expenditure. Historically, pharmaceutical manufacturers had been fiscally conservative, funding capital expansion through internal funds. Shifts in this measure following 1962 are primarily attributed by industry observers to the significant increase in diversification via acquisition.

Data were collected from published financial reports of each firm from the period 1950 to $1970-20$ years surrounding the change in regulation chosen for study. Breakpoints indicating change in strategy along key dimensions were identified through the use of cluster analysis, a procedure frequently used by strategy researchers to identify strategic change (Hambrick, 1984; Harrigan, 1985; Smith and Grimm, 1987). Firms were analysed individually using Ward's method of cluster analysis. This clustering method was considered the most appropriate of the several that might have been used (SAS Institute Inc., 1990) because it offers a straightforward translation of the idea of patterns in resource allocation. Ward's method clusters data by minimizing variance within clusters and maximizing variance across clusters. The algorithm involved initially separates the four measures for each year; it then joins clusters beginning with those that explain the least variance by existing separately. The procedure continues until all cases are joined in a single cluster. The researcher must decide when the programme begins to join clusters with inappropriately high variance, using the semipartial $R^{2}$ of each clustering iteration as an initial indicator of the appropriate clustering solution (number of clusters) (Hartigan, 1976). A review of the output indicated that a semipartial $R^{2}$ of greater than .1 represented a significant loss of explained variance in the next iteration of the programme. The final determination of the number of clusters was made much easier because of the easy interpretability of the clusters themselves (Evritt, 1980). No restrictions were placed on the algorithm to force sequential clusters. With one exception, however, when the procedure was terminated the breakpoints between clusters allowed them to be placed in longitudinal sequence, which suggests that the selected variables do capture cohesive strategic decisions made over time.

The one exception involved Parke-Davis. For this company, a significant drop in sales, coinciding with an increase in asset expenditures, led to a significant dip in liquid assets as a percentage of total from 1960 to 1963. This dip caused the clustering algorithm to identify the 1957-59 cluster as being much more similar to the 1964-69 cluster than to the 1960-63 cluster. Analysis of the remaining three variables suggested, however, that it was reasonable to maintain the three breakpoints involved, and thus the ultimate decision was that significant changes in strategy occurred in 1957, 1960 and 1964.

Table I summarizes the breaks identified in the pattern of each firm's strategic decisions, along with the descriptive statistics used to guide our decisions. As shown, the 1962 regulatory change coincided with the third or fourth strategic change made by the sample firms during the $1952-70$ study period. Based on the starred dates, we initially identified Merck and Parke-Davis as the fastest 
Table I. Initial categorization of firm responsiveness based on cluster analysis

\begin{tabular}{lllll}
\hline Firm & 1st strategy & 2nd strategy & 3rd strategy & 4th strategy \\
\hline $\begin{array}{l}\text { Merck } \\
\text { Parke-Davis }\end{array}$ & $1952-57(.582)^{b}$ & $1958-63(.115)$ & $1964^{*}-70$ & \\
SKF & $1952-56(.413)$ & $1957-59(.210)$ & $1960-63(.101)$ & $1964^{*-69}$ \\
Pfizer & $1952-56(.540)$ & $1957-64(.207)$ & $1965^{*-70}$ & \\
Schering & $1952-56(.442)$ & $1957-60(.211)$ & $1961-64(.121)$ & $1965^{*-70}$ \\
Abbott & $1952-54(.251)$ & $1955-58(.373)$ & $1959-65(.146)$ & $1966^{*-70}$ \\
\hline
\end{tabular}

Notes:

${ }^{a}$ Parke-Davis was purchased by Warner-Lambert in 1970, and so the last cluster terminates in 1969.

${ }^{b}$ Numbers in brackets are the semi-partial $R^{2}$ s. This is the loss in explained variance that occurs if the cluster is combined with the cluster to the right.

responders to legislative changes in 1962, with new strategic actions initiated in 1964. SKF and Pfizer, firms that show evidence of significant strategic change in 1965, were identified as midgroup responders. Schering and Abbott, with changes in 1966 and 1967 respectively, were identified as the slowest two firms to respond.

\section{Identifying Strategic Frames}

The second stage of preliminary analysis involved identifying the strategic frames used by the top management team of each firm. This task posed its own methodological challenges. Questionnaires can be used to ask about environmental and strategic changes (e.g. Milliken, 1990; Smith and Grimm, 1987), but the very act of asking an individual to reflect on an issue may cause his or her a priori interpretations to be re-evaluated, a problem that becomes more acute as the events of interest fall out of active memory (Golden, 1992). Real-time interviews avoid the retrospective nature of questionnaires, but also suffer from intervention effects. In fact, face-to-face contact heightens the distorting human tendency to impress the observer (Eden et al., 1993). Ethnographic approaches to the study of changing interpretations provide a less obtrusive method of study (Bartunek, 1984; Meyer, 1982; Scheid-Cook, 1992), though impression management cannot be discounted. In addition, these studies are even more time-consuming than interviews and rely more heavily on subjective interpretations by the researcher.

We were attracted to studying a stressful event that occurred over thirty years ago because the impact of the focal event and possible confounding effects were easier to identify after the passage of time. None of the four methods just described are very practical in this circumstance, however, and thus we were drawn to a fourth methodological alternative, content analysis of documents written during the period of interest. Documents are a real-time, non-intrusive indicator of the interpretations of top managers that are especially attractive when, as in this case, other data sources (interviews, questionnaires, direct observations, etc.) are not available. The basic assumption is that the subjects that decision makers discuss in communications such as letters to shareholders reflect 
concerns of importance to the speaker. This assumption dates back to the first recorded use of content analysis, an investigation of the heretical content of new hymns in eighteenth-century Sweden (Woodrum, 1984).

Annual reports are the most obvious documentary data source for longitudinal studies, since they are produced by many companies at the same time of the year and they are readily available. In addition, we believe that annual reports and other public documents are an important forum in which strategic frames are articulated. They both reflect and help create needed commonalities in the interpretation of events. Further, they have been used in past research to assess and explain corporate strategies (Bowman, 1984; Fahey and Narayanan, 1989; Fiol, 1989; Lant et al., 1992), to identify key arenas of competition (BirnbaumMore and Weiss, 1990) and to explore causal reasoning within firms (Bettman and Weitz, 1983; Clapham and Schwenk, 1991).

To expand the data set available from annual reports, we also tried to locate public speeches made by representatives of the study firms in our study period. None of the six firms was able to provide transcripts of speeches from the time period studied. ${ }^{[2]}$ There were, however, a total of 19 speeches from this time period published in the Wall Street Transcripts, a publication that provides a full record of many executive speeches to securities analysts and similar audiences. At least two speeches were available for each of the six firms in the sample, with the exception of Schering, for which we found only one.

The exact authorship of both letters to shareholders and speeches is open to question, but when a shared strategic frame is the unit of analysis, ambiguity about authorship of such documents is not particularly problematic. The notion of epistemic community discussed earlier, and increased emphasis on the fact that the leadership of larger organizations is dispersed among many individuals (Hambrick and Mason, 1984), make it plausible to use such documents as an indicator of shared understanding.

Annual reports and speeches to analysts are more problematic because they are persuasive documents and subject to deliberate distortion; but persuasion and distortion accompany all possible data sources. We have noted already that biased recall and impression management can have contaminating effects on data drawn from questionnaires, interviews and participant observations. Even accounting data and financial information can be slanted to present the firm in the best possible light. While we recognize that annual reports and speeches are explicitly persuasive, we echo Giere's (1988) argument that unrealistic theoretic statements in science are constrained by a broad body of 'common observation'. Securities analysts, institutional investors, the business press and the Securities and Exchange Commission all constrain errors of commission and omission. Salancik and Meindl (1984) present evidence that firms are rewarded for being truthful in these circumstances. The bottom line is that we chose to study a set of documents that are not the ideal indicator of shared belief, but no ideal data source exists.

Despite their limitations, these documents provided a very interesting source of data for study. Even before beginning detailed coding, initial analysis of statements made in the documents for Pfizer, Abbott and Parke-Davis provided insights that required a change in the original categorization of faster versus 
slower responders. (That is, we found we had an error rate of 50 per cent using a method commonly used in strategy research to identify strategic change.) Beginning with the general premise that topics covered in the letters to shareholders and speech transcripts reflect issues of importance to top managers, we looked for statements concerning the legislation and related events (hearings, introductions of earlier versions of the legislation, etc.) in the documents of each firm. Letters and speeches for Pfizer and Abbott during 1959-61 contained several statements concerning senate investigations of the industry and the introduction of the Kefauver bill in early $1961 .{ }^{[3]}$ Pfizer letters and speeches following the 1962 change in legislation make no mention of it. Abbott continued to mention the legislation but only as a side issue; statements concerning the potential change in legislation during the 1959-61 time period were much more frequent and substantial than statements made after 1961. In short, the 1965 change in action for Pfizer and 1967 change for Abbott appear not to be directly related to the new legislation that provided the stimulus event for this study. Content analysis indicates that both firms made a proactive response to initial legislative moves rather than wait for the actual enactment of the legislation in 1962. This conclusion was corroborated by a systematic study of business press and industry articles about each firm during this same time period. Both companies therefore were recategorized as faster responders.

A review of the content of Parke-Davis documents was even more interesting. The data reveal no references to regulatory issues over the entire study period. This company's statements were focused on relative lack of $\mathrm{R} \& \mathrm{D}$ productivity and declining sales of Chloromycetin, their primary product. Complete lack of attention to legislative events, combined with numerous statements made regarding R\&D, suggest that their 1964 change in strategy was not strongly motivated by the legislative change that interested us as a stressful event. This firm was therefore excluded from comparative assessment of response to stressful legislation. Of course, Parke-Davis did compete in an environment almost all other observers felt was significantly restricted by new legislation. This environment presumably had an impact on the outcome, if not the formulation, of their strategy. It is well to remember, however, that even 'major' changes in the environment do not have a homogeneous effect on all firms.

Given the cross-check of quantitative measures of change in allocation of strategic resources with qualitative content pertaining to government actions, our final classification is shown in table II. Pfizer and Abbott are identified as fast responders to new regulation with 1961 changes in strategic action anticipating 1962 legislation. Merck, SKF and Schering are classified as slower responders with changes in action occurring in 1964, 1965 and 1966, respectively. ParkeDavis must be analysed separately and is addressed in the discussion section of this paper.

\section{EMPIRICAL EVIDENCE OF THE INTERPRETIVE PRECURSORS TO STRATEGIC CHANGE}

Once it was clear that there were significant differences in the timing of response to 1962 regulatory changes among pharmaceutical firms, we wanted to determine if these responses could be explained in terms of the theoretic ideas

(C) Blackwell Publishers Ltd 1997 
Table II. Re-assignment of firms based on content analysis

\begin{tabular}{|c|c|c|c|}
\hline Response time & Name of firm & Years & Description \\
\hline \multirow[t]{2}{*}{ Faster response } & Pfizer & $\begin{array}{l}1957-60 \\
1961-64\end{array}$ & $\begin{array}{l}\text { Internal product line expansion. } \\
\text { Internal foreign expansion } \\
\text { Diversification via acquisition. } \\
\text { Foreign expansion via acquisition }\end{array}$ \\
\hline & Abbott & $\begin{array}{l}1957-60 \\
1961-66\end{array}$ & $\begin{array}{l}\text { Internal product line expansion. } \\
\text { Internal foreign expansion } \\
\text { Product line expansion via } \\
\text { acquisition. Diversification via } \\
\text { acquisition. Continued foreign } \\
\text { expansion }\end{array}$ \\
\hline \multirow[t]{3}{*}{ Slower response } & Merck & $\begin{array}{l}1958-63 \\
1964-70\end{array}$ & $\begin{array}{l}\text { Internal product line expansion. } \\
\text { Limited foreign expansion } \\
\text { Diversification via acquisition. } \\
\text { Limited foreign expansion }\end{array}$ \\
\hline & SKF & $\begin{array}{l}1957-64 \\
1965-70\end{array}$ & $\begin{array}{l}\text { Internal product line expansion } \\
\text { Foreign expansion. Diversification } \\
\text { via acquisition }\end{array}$ \\
\hline & Schering & $\begin{array}{l}1959-65 \\
1966-70\end{array}$ & $\begin{array}{l}\text { Internal foreign expansion. Internal } \\
\text { product line expansion } \\
\text { Product line expansion via } \\
\text { acquisition. Diversification via } \\
\text { acquisition. Foreign expansion via } \\
\text { joint-venture acquisition }\end{array}$ \\
\hline Non-response & Parke-Davis & & \\
\hline
\end{tabular}

summarized in figure 1. The figure suggested three points at which the interpretive processes of faster responding firms might be significantly different from slower firms. Faster firms might: (1) more rapidly notice changes in the environment; (2) more quickly interpret changes as significant; or (3) more quickly determine that the stress associated with the new event merited action. Differences at even one of these points might explain differences in the timing of strategic action; alternatively, faster firms might be distinguished from slower firms by multiple indicators of difference. To address these issues we looked more closely at statements made in annual reports and the Wall Street Transcripts.

\section{Causal Mapping Methodology}

Of the several procedures available to systematically content analyse written documents (Huff, 1990), we chose to focus on causal reasoning under the assumption that firms typically initiate strategic actions based on the shared belief that they will cause desirable changes; many other organization researchers have made the same assumption (e.g. Allard Poesi, 1994; Barr et al., 1992; Bougon et al., 1977; Eden, 1993; Ehlinger, 1994; Jenkins, 1994; Laukkanen, 1994; Markoczy and Goldberg, 1995; Narayanan and Fahey, 1990; Salancik and Meindl, 1984; Shrivastava and Lin, 1984). The method of 'cause mapping' we 
Table III. Coding categories

\begin{tabular}{ll}
\hline Symbol & Definition \\
\hline$/+/$ & Positively affects \\
$/-/$ & Negatively affects \\
$/ \ominus /$ & Will not hurt, does not prevent, is not harmful to \\
$/ \oplus /$ & Will not help, does not promote, is of no benefit to \\
$/ \mathrm{a} /$ & May or may not be related to, affects indeterminably \\
$/ \mathrm{m} /$ & Affects in some non-zero way \\
$/ 0 /$ & Does not matter for, has no affect on, has no relation \\
$/=/$ & Is an equivalent to, is defined as* \\
$/ \mathrm{e} /$ & Is an example of, is one member of* \\
\hline
\end{tabular}

Note:

* Categories not used by Axelrod.

used was initially developed by Axelrod (1976) and elaborated by Huff et al. (1990). The process is time-consuming, but the resulting maps provide a parsimonious synthesis of a great deal of material.

The procedure requires that all statements of relationship in the document analysed be identified by the coder. The nature of the relationship is placed into one of the nine categories identified in table III. After all relational statements have been identified, the linked concepts are examined. Those judged to be equivalent are given the same code. A cause map is then constructed by connecting coded concepts with arrows and labelling the arrows with the appropriate symbol for the type of relationship. As a simple example; the sentence 'Substantial construction was undertaken in 1961 for the manufacture of new products as well as increased capacity to meet rising demands for established ones', would be coded as follows:

Substantial construction undertaken in 1961 (1.a)

Substantial construction undertaken in $1961(1 . \mathrm{a})$
+ [ability to] manufacture new products (1.b)

+ [ability to] meet rising demand for established products (1.c)

and then represented in graphical form as shown below:

Substantial construction undertaken in 1961 (1.a)

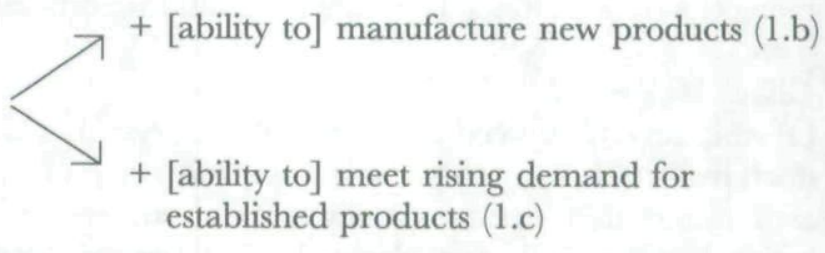

The coding manual also makes provisions for linkages that are not directly stated, but are implied by context. These coder decisions are distinguished on the map by use of a dotted, rather than a solid arrow. In addition, sometimes the ultimate effect of a chain of reasoning is implied rather than explicit. The 
coding procedure therefore allows the coder to specify a positive or negative impact on the 'utility' of some actor or entity. All inferences, even linking words such as those in the above example, are indicated by brackets, which signify a departure from the source material.

The documents utilized for coding in this study were the 42 letters to shareholders (LTS) from the annual reports for each firm from 1960 to 1966 (one year prior to the earliest response among the firms and one year after the latest response) and transcripts of the eight speeches recorded in the Wall Street Transcript (WST) (out of 19) that included references to government legislation. Letters to shareholders averaged two $8.5^{\prime \prime} \times 11^{\prime \prime}$ typed pages of text while the WSTs averaged six $8.5^{\prime \prime} \times 11^{\prime \prime}$ typed pages. In total, approximately 132 pages of text were coded. Comparisons of maps from both data sources show consistency in causal assertions for all six firms studied, a consistency in causal reasoning also found by Axelrod (1976) and his associates. Material from the WST speeches was therefore added to LTS of the same year.

Document coding was performed by two independent research assistants unaware of the research questions. Each coder was trained separately in the coding process by the first author. Two WST speeches from sample firms were coded by both coders to ascertain intercoder reliability. These texts were among the longest and most complicated documents to be coded, consisting of 122 total statements. Based on Robinson's (1957) measure of agreement, which is also used by Axelrod (1976), intercoder agreement on the number of codable assertions was 82 per cent. This is a reasonable degree of reliability, though not outstanding; the differences between coders, however, were primarily due to two sentences with particularly subtle causal assertions. Had the coders agreed on these two statements, reliability would have been 89 per cent, well within the range of acceptability. Agreement on which part of the statement contained the causal concept was 98 per cent. Identification of the part of the statement containing the effect was 97 per cent. Agreement as to the sign of the causal relationship was 88 per cent, with most differences involving subtle signs such as 'no effect on' and 'no negative effect on'.

Once training was satisfactorily established, the remaining documents were divided between the coders, who completed all coding independently. In analysing the results we were guided by the three questions drawn from figure 1: (1) Do firms that quickly take action more rapidly identify changes in their environments? (2) Do they more quickly interpret unfamiliar stimuli as important?, and/or (3) do they more rapidly identify stressful consequences of new stimuli?

Finding 1: Faster firms could not be distinguished from other firms in our data set by their attention to legislation change.

The most straightforward link between the interpretation of an event and new strategic action is direct stimulus-response. That is, the most basic hypothesis relevant to our interest in the length of time it takes firms to respond to environment change would be that the strategic frame used by faster responding firms will contain references to a precipitating environmental event prior to slower responding firms. Figure 1 proposes, however, that the simple process of noticing 
significant changes in the environment is not in and of itself a sufficient trigger for adaptive changes in strategy.

In analysing the maps in the data set, any and all concepts dealing with proposed or actual legislation were identified, regardless of how they were connected to other concepts. Because the faster responders changed in 1961, both the 1960 and 1961 maps for all sample firms were analysed. The maps of both early and late responders make references to the proposed legislation as early as 1960. Only Parke-Davis, as noted above, failed to attend to either the pending legislation or to its enactment.

Finding 2: A necessary condition for strategic actions in our sample is that firms perceive their welfare is directly affected by environmental change.

As indicated in table II, the faster firms (Pfizer and Abbott) actually responded in 1961, prior to the 1962 change in legislation. Therefore, the 1961 cause maps of each firm are examined. These maps show that the proposed change in legislation is directly linked to concepts affecting firm performance and well-being in the faster responding firms. In analysing the maps, strength of association was determined by the type of linkage (a direct, stated association, versus an indirect, implied association), the strength of the linkage code (e.g. + and - versus $\ominus$ and $\oplus$ ) and the number of linkages between the concepts surrounding the new legislation and concepts about performance and well-being (the greater the number of linkages, the stronger the association).

The 1961 cause map of Pfizer (excerpted in figure 2) can be used to illustrate the type of associations displayed. The bill itself (concept 47e) has a total of nine linkages to Pfizer utility (1b) and Pfizer's growth (2g). In addition to the seven direct linkages to Pfizer utility $(47 \mathrm{~m} .1-47 \mathrm{~m} .3 ; 47 \mathrm{n} .1-47 \mathrm{n} .4)$, the bill is seen as an example of government actions which, in turn, are causing both problems and opportunities for the firm, of which Pfizer is 'aware' $(47 \mathrm{~h}$ and $47 \mathrm{j}$ ) and is 'preparing for' (47i and 47k). These preparations are seen as having a direct and positive effect on Pfizer's growth (a performance measure). Abbott's maps reflect similar causal associations between the proposed legislation and firm performance. In this company's 1961 map, the proposed legislation is directly linked to firm utility and to R\&D, a concept that is in turn linked directly and strongly to measures of firm performance.

The 1961 maps of the three slower responding firms do not exhibit this type of association. The cause map of Schering does not contain any concepts related to the legislation. Merck's map contains concepts related to the senate subcommittee investigation of the pharmaceutical industry that preceded the introduction of the legislation, but not to the legislation itself. While this map does demonstrate an understanding of the implications of the investigation, the implications are all linked to industry utility. There is no connection between the investigation and concepts related to firm specific performance. Finally, SKF's map also contains legislation concepts but, like Merck, this understanding is not related to firm-specific performance or well-being.

We then looked at the 1962 maps of the slower responding firms. If significant connections between legislation concepts and measures of firm performance existed as soon as the bill was adopted, the assertion that a distinguishing charac-

(C) Blackwell Publishers Ltd 1997 


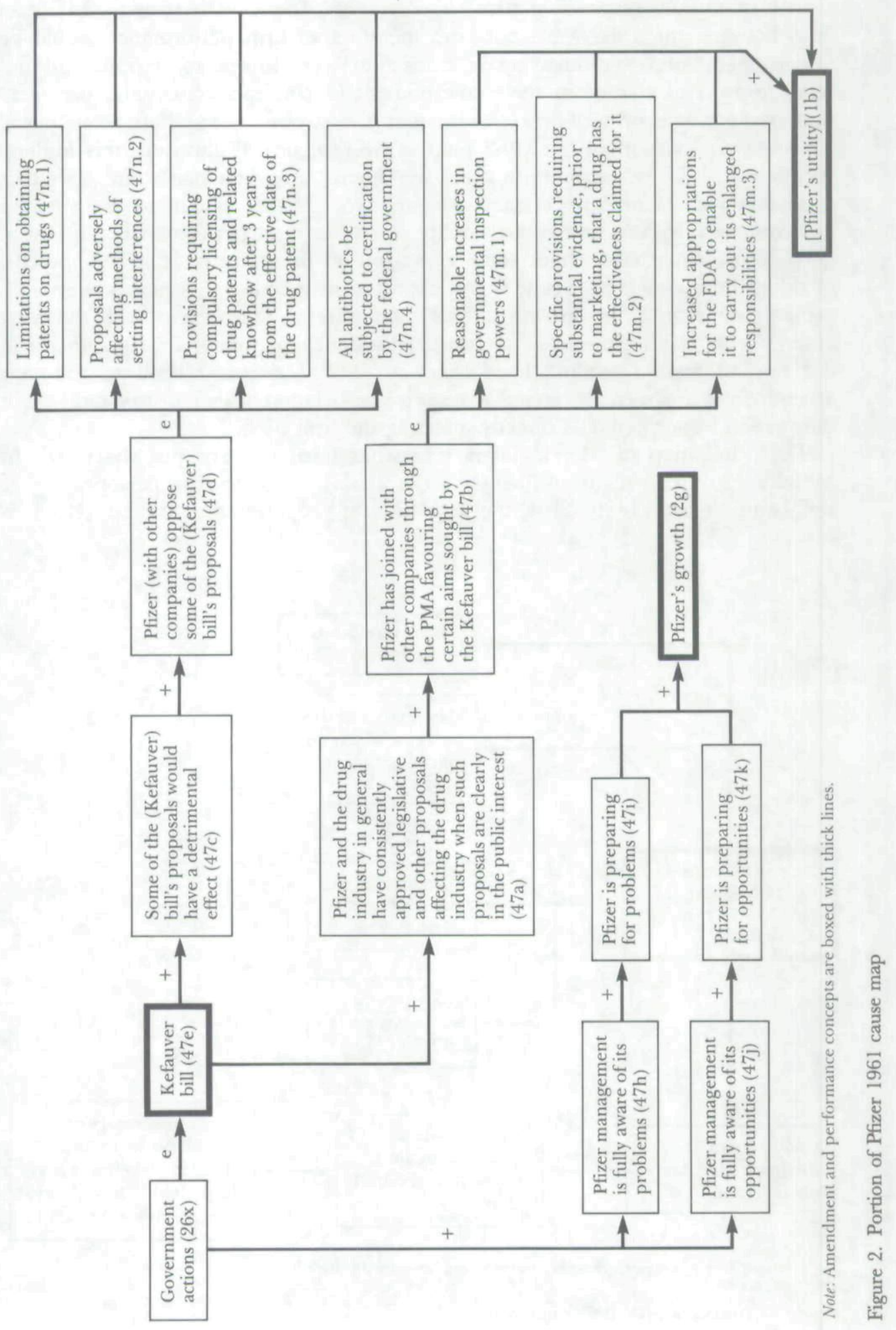


teristic of rapidly responding firms is a strategic frame with strong and direct links between the 1962 legislation and measures of firm performance would be undermined. However, once again firms that were slower to respond did not relate aspects of change in their environment to concepts concerning organization performance or well-being, even after the stressful event had taken place. The relevant portion of the 1962 map of SKF (figure 3) illustrates this finding. In this map SKF is 'prepared to speak out against any such legislation' (25o) that it equates with being 'unnecessary or restrictive...' (25q), but these concepts are not connected in any way to firm utility or measures of performance. The event $(25 \mathrm{k})$ is also expected to have some effect $(\mathrm{m})$ on the industry (25l) and the cost of doing business (24f.1) yet it is not expected to increase $(\oplus)$ alarm over SKF profitability (25n.2) or growth (25n.1). Schering's interpretation of the new amendments is also unrelated to firm performance or utility. In 1961 this firm did not address impending legislation; by 1962 concepts related to the new amendments are seen as having a negative association with industry utility, but they are not interpreted as directly affecting the firm itself.

The 1962 map of Merck differs somewhat from the two just described. In Merck's 1962 map (figure 4), legislation is weakly linked to firm performance or well-being at two points. First, the legislation 'if properly administered' (18a.1) is

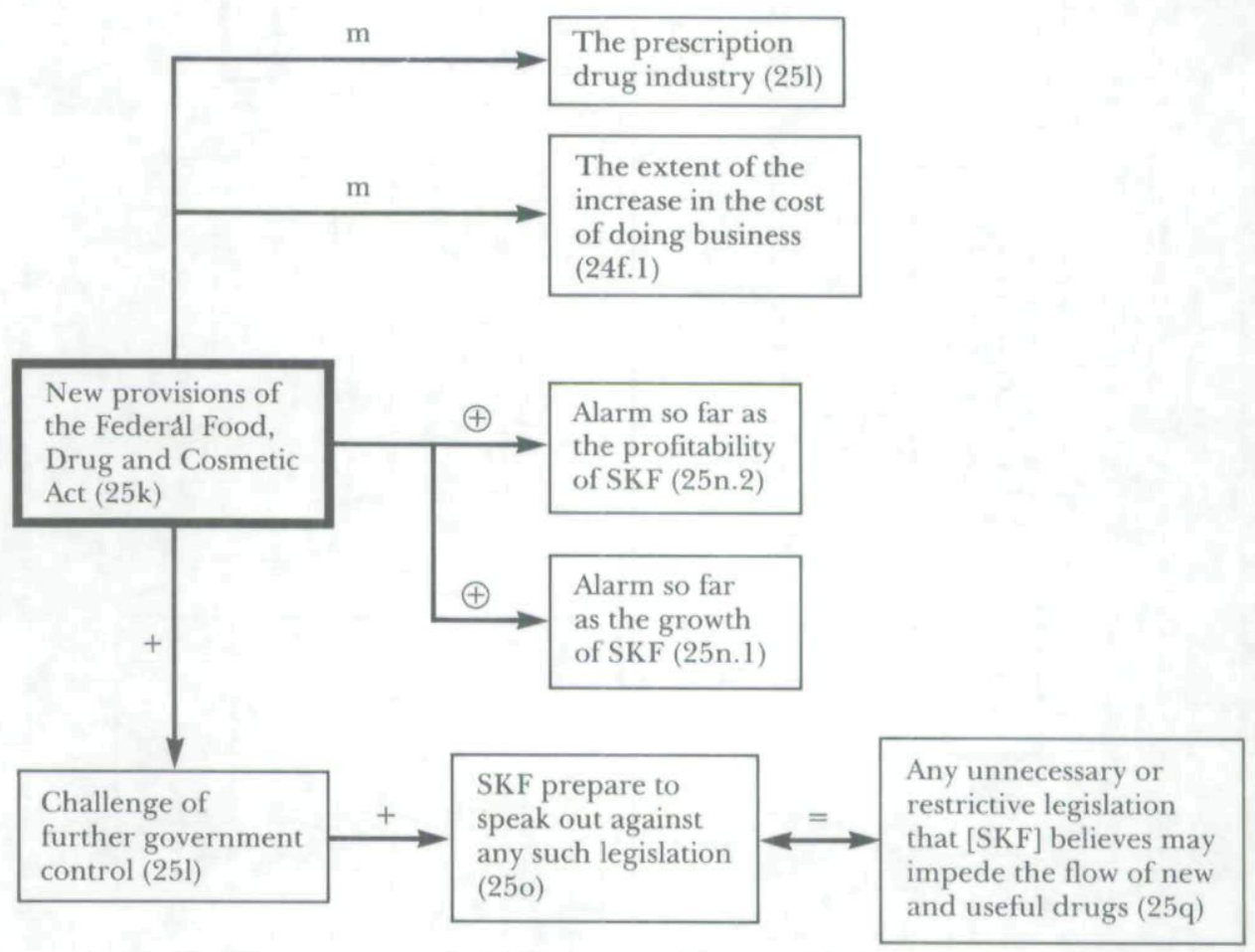

Note: Amendment and performance concepts are boxed with thick lines.

Figure 3. Portion of SKF 1962 cause map

(C) Blackwell Publishers Ltd 1997 


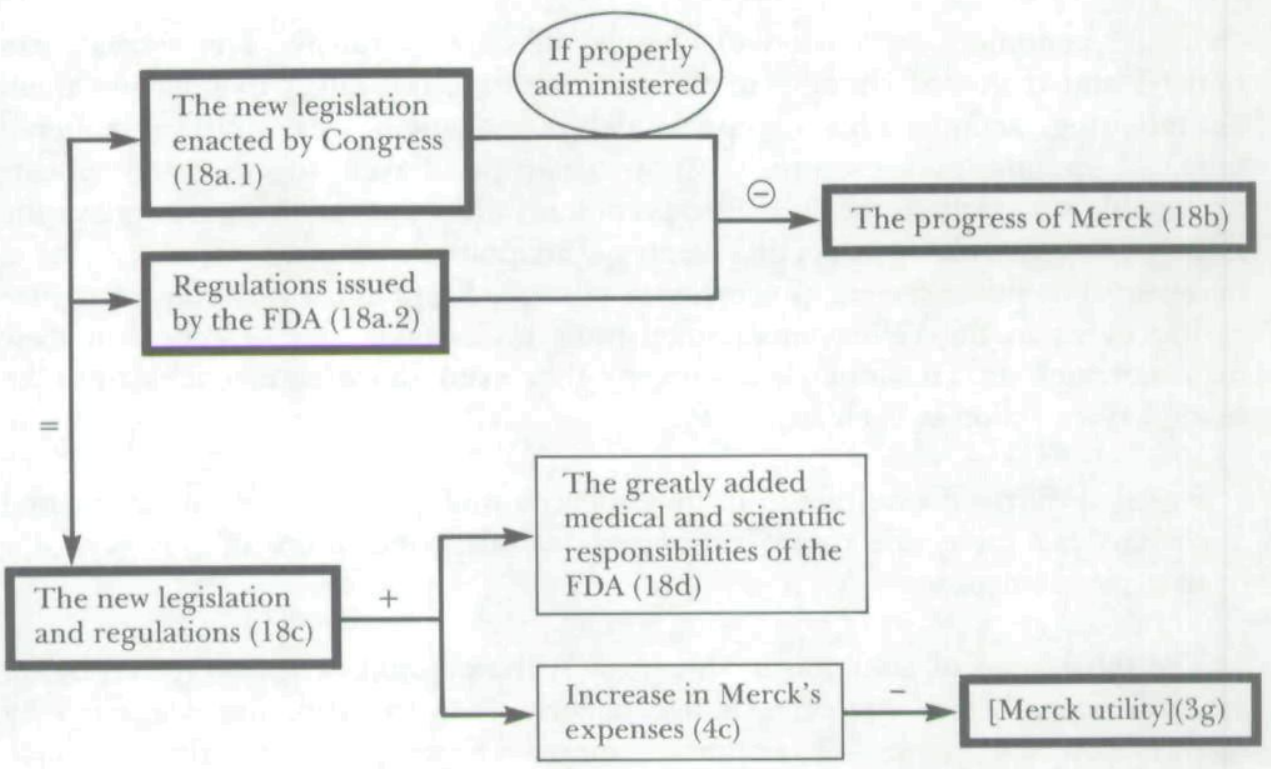

Note: Amendment and performance concepts are boxed with thick lines.

Figure 4. Portion of Merck 1962 cause map

weakly linked by a 'does not have a negative affect on' code $(\Theta)$ to 'the progress of Merck' (18b), an implied performance indicator. This weak causal link is a more peripheral connection between the stimulus event and firm performance than found in the rapidly responding firms. It is also weak when compared to the stronger linkages other concepts have to performance measures in the complete map. A second relevant link comes from the expectation that legislation will increase company expenses (4c), a concept that is in turn directly linked to firm utility $(3 \mathrm{~g})$. However, given that the regulation itself is not interpreted as significantly affecting the progress of the firm, this single link does not suggest that the legislation is interpreted as significantly affecting this measure of performance.

In sum, the maps, taken as an indictor of strategic frames, indicate that attention was being paid to the 1962 change in legislation by all five responding firms. However, slower responding firms do not initially interpret new regulation as affecting firm level performance or well-being in any significant way, while firms responding more quickly do interpret those changes as having a direct impact on firm performance and well-being. To use Milliken's (1987, 1990) term, there was no 'state uncertainty' for pharmaceutical firms in the early 1960 s. It appears from the data that the slower firms were well aware of new legislation, but did not understand or believe its implications until much later than their competitors.

A recent empirical study by Barr et al. (1992) provides empirical support for the importance of this additional interpretive step. In this study of two railroad companies facing increasing competition, it was found that both companies quickly noticed changes in the transportation industry in the period following World War II. However, only the firm that survived into the 1970s linked 
changing conditions to a need to change their own strategy. The second firm noticed and discussed changes in the environment, but failed to interpret them as requiring action. This company delayed changing its strategy, suffered financial decline and eventually went bankrupt. Taken together, it appears reasonable to conclude that it is interpretation rather than noticing that plays the most important role in triggering strategic adaptation; noticing appears to be a necessary but not sufficient precursor to change. Firms must not only recognize a new event in the environment, they must understand its connection to their own activities. In fact, our data suggests that even more connections must be made before action is likely.

Finding 3: Firms do not act until they identify multiple effects of environmental change and these effects are supported by other indicators of the need for strategic change.

The third focus of attention in this study is the amount of stress created by an external event before strategic change occurs. Two scenarios are suggested by research on the causes of continuing inertia. First it may be that a single perceived consequence of an external event is not sufficient to significantly change performance expectations for the firm. At the individual level it has been argued that actors are not completely open to developing new ideas for action because so much of the individual's identity and activity are based on current understandings (Anderson et al., 1980; Ross et al., 1975). The general consensus is that there must be significant modification in understanding before adjustments in activity are made. Analogous reasoning at the organization level suggests that a change in the environment may have to be interpreted as having many significant connections to concepts of firm performance and/or well-being.

Our data support the idea, formalized in figure 1, that attention to multiple direct effects of the environment must precede strategic change. To investigate this idea, the maps from the three years up to and including the year of change in strategic action were examined for each of the five responding firms. The 1962 legislation was considered to have multiple direct effects if there was more than one direct linkage to concepts about firm performance or well-being. All five firms exhibited such linkages. Once again the 1961 map of Pfizer (figure 2) is illustrative. The Kefauver bill (47e) contains proposals that Pfizer opposes (47d) as well as some that Pfizer supports (47b). Leading from these concepts are seven aspects of the bill that are interpreted as having strong direct effects on Pfizer's utility (1b).

The remaining maps provide less dramatic support for the idea that identifying multiple impacts will precede strategic change. Table IV lists each firm and the number of linkages between legislative concepts and firm performance and well-being in each year analysed. As shown, Abbott's change in strategy in 1961 is accompanied by two links between legislation and the firm. SKF and Merck each establishes two links the year before new actions take place. Schering makes two such connections in 1964, but does not change strategy until 1966.

A second scenario about the type of stress that must precede strategic change involves the linkage between a stressful event and other events that are also perceived to have an impact on performance. If one event is perceived to have relatively few direct connections to firm performance, it may have to be seen in

(C) Blackwell Publishers Ltd 1997 
Table IV. Number of linkages between legislative concepts and measures of performance and well-being

\begin{tabular}{llllllll}
\hline & 1960 & 1961 & 1962 & 1963 & 1964 & 1965 & 1966 \\
\hline Merck & & & 0 & 2 & 0 & & \\
SKF & 0 & 7 & & 0 & 2 & 0 & \\
Pfizer & 0 & & & & 2 & 0 & 0 \\
Schering & 0 & 2 & & & & & \\
Abbott & 0 & & & & &
\end{tabular}

association with other events that also impact performance measures before strategic change occurs. In examining this idea, the maps for the three years up to and including the year of change in strategic action were again analysed. All concepts with a strong, direct link to measures of firm performance or well-being were traced back to their concept of origin and these concepts were examined for connections to the new legislation.

The overall results of this analysis are that multiple maps exhibit the presence of more than one triggering event before a change in strategic action. This is a finding that strongly supports the idea that stress must accumulate before strategic change occurs (Huff et al., 1992). The 1964 map of SKF (figure 5) illustrates the kind of reasoning involved. The map shows three event interpreted by firm management as impacting SKF utility (lg). First, as discussed earlier, the 1962 amendments (25k) affect utility through a decline in new medicines (26i) brought on by increased paperwork (26h.2) and approval times (26k). A second, related event is the withdrawal, by the FDA, of SKF's drug Parnate (28i). This is related to the new regulations by a common relationship to the FDA because all paperwork for drug approval is submitted to the FDA. Also related to the FDA and SKF utility is 'new regulations of the Department of Health, Education, and Welfare' (25o), which increase the administrative problems 'now harassing the FDA and the industry' (29a). In short, as the firm changes its strategy, three different events, all related to FDA activities, are interpreted as having strong negative links to the utility of the firm.

As a summary of the other data supporting this finding, table $\mathrm{V}$ lists each sample firm and the related events found in the maps immediately prior to that firm's change in strategic action. All concepts were related through some form of government institution or action. It must be noted that it was not until 1965, one year after the change in strategy we identified through examining the pattern of resource allocation, that Merck's maps indicate concern with any other issues. However, the maps do reveal that those issues are connected to a long-standing concern over 'continuing government intervention' in the industry that may indicate some unstated concern with these other events prior to 1965 .

\section{DISCUSSION}

The purpose of this study was to use the ideas of strategic frames and stress and inertia to explore the temporal relationship between firm level interpretation of 


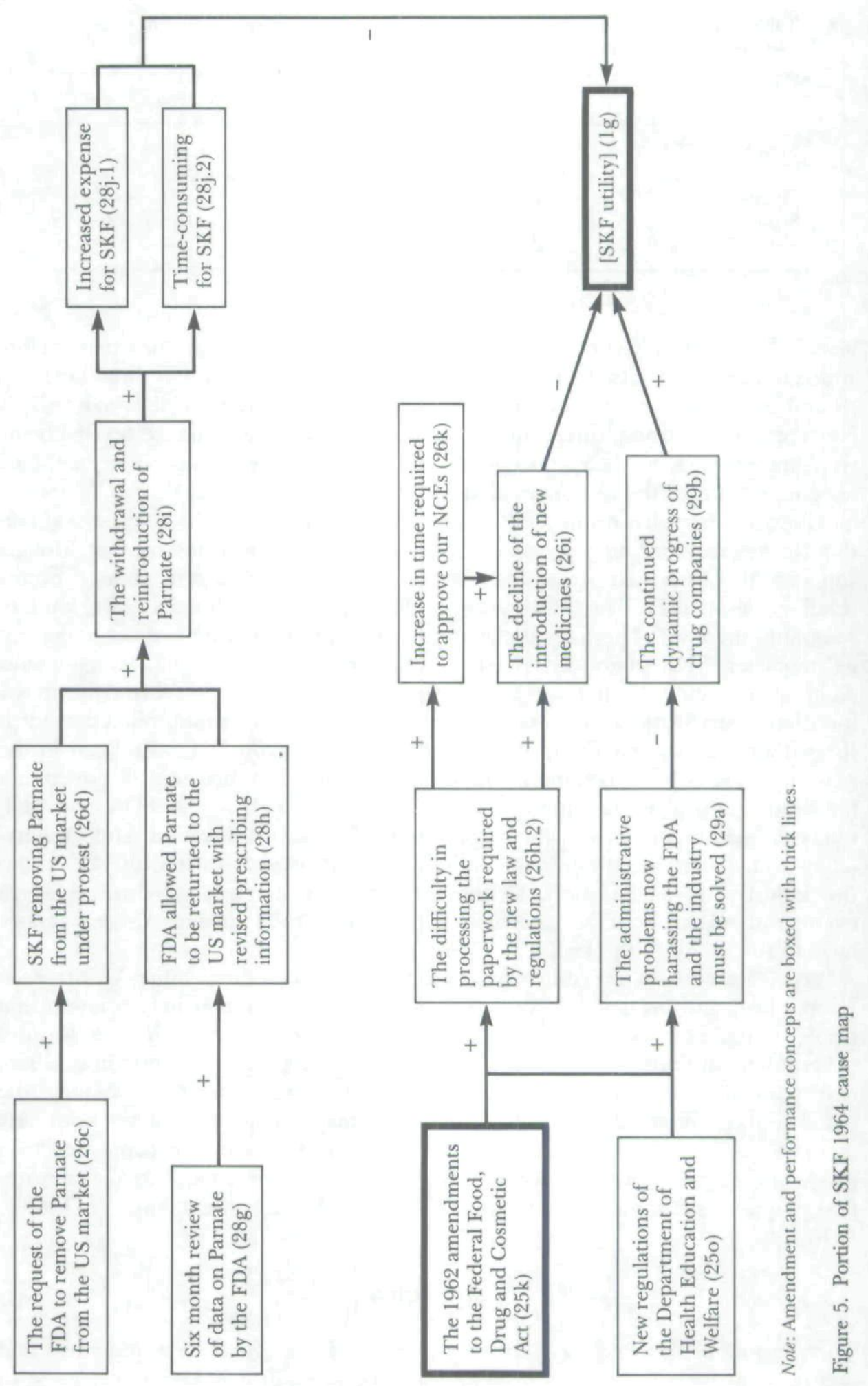


Table V. Related events by firm

\begin{tabular}{|c|c|}
\hline Firm & Events \\
\hline Merck & 1962 Amendment, Medicare 1965, 'other far-reaching legislation' 1965 \\
\hline SKF & $\begin{array}{l}1962 \text { Amendment, withdrawal of Parnate (major product) by the } \\
\text { government 1964, changes in HEW regulations } 1964\end{array}$ \\
\hline Pfizer & $\begin{array}{l}\text { Delany Food Additives Amendment 1958, Government contracts with } \\
\text { foreign firm for tetracycline (a Pfizer patented product) 1960, 1961 proposed } \\
\text { amendment (Kefauver bill) }\end{array}$ \\
\hline Schering & 1962 Amendment, overseas regulatory changes 1964, Medicare, 1965 \\
\hline Abbott & $\begin{array}{l}\text { Delany Food Additives Amendment 1958, Proposed change in taxation of } \\
\text { overseas earnings 1961, } 1961 \text { proposed amendment (Kefauver bill) }\end{array}$ \\
\hline
\end{tabular}

an important environmental event and significant changes in strategy. We began by referring to the basic tenet of strategic management that firms should alter their strategies to adapt to new conditions, but noted that there exists wide variation in the timing of such an adjustment across firms in the same industry (Ginsberg and Buchholtz, 1990; Haveman, 1992; Smith and Grimm, 1987). Many models of strategic change and problem formulation include a trigger which sets the process of change in motion (Ginsberg, 1988; Lyles, 1981; Mintzberg et al., 1976). However, the nature of the triggering process has not been well defined. This study significantly expands our understanding of the triggering or timing of strategic response by suggesting that response is closely linked to changes in interpretation that appear in the strategic frames of the organization. How a newly recognized event is incorporated into the strategic frame, in particular how it relates to the performance of the firm and to other events that impact performance, is more closely associated with variations in the timing of strategic response across firms than noticing the event. In other words, the old strategic frames, which are unlikely to hold concepts corresponding to a new environmental event, must change in quite specific ways before new action is initiated. Further, the types of changes in interpretation identified through the maps are consistent with extant theories of stress and inertia as factors in the timing of change.

Several studies have sought to investigate the potential of cognitive maps to both provide insights for theory development and to aid management practice. Use of cognitive mapping for theory development has, for example, revealed correlations between industry structure and managers' understanding of the environment (Calori et al., 1994; Porac et al., 1989; Reger and Huff, 1993) and between cognitive maps and firm performance (Barr et al., 1992; Hall, 1984). Mapping techniques have also been used to aid managers in problem resolution and strategic planning by highlighting previously unstated, or unrecognized, beliefs (e.g. Eden, 1990, 1993).

In this study, we utilize mapping techniques to identify organization level beliefs (strategic frames) and then identify patterns of change in these maps that reflect changes in noticing and interpretation. Our results reveal a temporal rela- 
tionship between these patterns of change in maps and changes in strategic action, and thus represent an important step forward in our understanding of the link between interpretation and action.

The changes in strategic frames associated with the timing of strategic change identified in this study are directly consistent with stress and inertia theories of change which suggest that inertial forces that build in firms over time work to prevent second order change until they are surpassed by higher levels of stress (Ginsberg, 1988; Huff et al., 1992). The data indicate that stress may follow from either or both of two types of strategic frame characteristics. First, the interpreted strength of the impacts of the event on the firm appears to be moderately important to the timing of response. The maps of all of the five responding firms exhibited multiple links between amendment concepts and firm performance prior to strategic change, suggesting that the event was interpreted as having a very strong impact on the firm. Further, while the maps of faster responding firms did not exhibit stronger links between the event and firm performance than slower responding firms, they did exhibit multiple links prior to the slower firms. This suggests that strength of impact, represented in this study by the number of perceived impacts on the firm, is an important trigger to change.

Another observation related to stress involves the effect of multiple events. The five firms in our sample related the change in legislation to several other events, all of which exhibited direct links to firm performance or well-being prior to changing strategy. The immediate implication of these results is that these multiple linkages reflect increased levels of stress that are likely to surpass existing levels of inertia and trigger change. Because change did not occur until after these links appeared in the maps, it adds to the argument that stress is a necessary component to the triggering of change.

A broader implication of these results is that strategy researchers must look more closely at what we mean by the term 'response'. First, we found a very large discrepancy between quantitative and qualitative indicators of strategic change. Second, more detailed analysis of the maps suggested that strategic actions which might easily be attributed to widely recognized changes in the industry were not necessarily made in response to legislation alone. Rather, change in strategy can be linked to the effects of numerous, related events. For example, early responders undertook a change in strategy prior to actual enactment of the 1962 version of the bill. It was the introduction of an earlier version of the bill that, combined with the perceived impacts of other prior government events, increased the pressure for change beyond the level of inertia. Late responders, whose maps indicated no prior concern regarding government actions prior to the change in legislation, did not change strategy until the occurrence of additional governmental actions which were linked, in the maps, to firm performance.

The 'non-response' of Parke-Davis also highlights the importance of related events and trends to organizational response. As noted earlier, the maps of Parke-Davis suggest that their 1964 change in strategy was not strongly motivated by legislative change. Rather, concepts related to performance and well-being during the time were concerned with $\mathrm{R} \& \mathrm{D}$, a lack of new product development (NPD), and declining sales of their primary product. Parke-Davis' R\&D efforts had not resulted in a significant new product since the late 1950s. 
Further, 43 per cent of sales in 1960 was from a single product, Chloromycetin, which was due to come off patent in 1966, and was already suffering declines in sales overseas where patent protection was less strictly enforced. Certainly the lack of NPD could have been exacerbated by the change in legislation. However, because the 'event' of a lack of NPD began prior to 1962, the effect from the legislation was, perhaps, made less salient. In fact, the 1964 change in strategy undertaken by this firm, an increase in diversification, is not accompanied by changes in map concepts related to the external environment. This suggests that the change in strategy was less a response to a change in the external environment than it was a response to trends in the internal environment - the continued lack of NPD coupled with the impending loss of patent protection on, and declining sales of, their primary product. While Parke-Davis may not have 'responded' to the change in legislation, it is interesting that its maps are consistent with the theory of interpretation and change suggested by the maps of the other five firms. Before strategic change, three concepts $(R \& D$, NPD and patents) in the maps are strongly and directly linked to Parke-Davis' performance and well-being. Further, concepts related to both R\&D and concerns about Chloromycetin can be traced back to lack of NPD; differential issues with a common root.

In general, the results of analysis of the maps from all firms suggest that actions undertaken following a significant event in the environment are not just a response to that event. Rather, strategic change responds to a perceived trend in the environment, in this case increased governmental action in the external environment or a lack of NPD in the internal environment, that impacts firm performance. Although beyond the scope of this study, action may also reflect the constellation of external stakeholders who are making their own interpretation of these events. The experience of early responders may also play a role, though this influence is not explicit in the data set we used. These complexities are consistent not only with stress/inertia theories of strategic change, but also with other theories which suggest significant changes in strategy are undertaken in response to shifts in the environment in general, while response to specific events is limited to activities of a more tactical nature (Meyer, 1982).

Several questions are raised by this study that serve as directions for continued research on the link between strategic frames and strategic response. First, why the strategic frames of some firms quickly associated environmental change with performance concepts while others did not is unclear from our analysis. We purposely selected an event for study that was specifically designed to impact the manner in which all members of the industry operated. Thus, one would expect a greater consistency across firms in their realization that this event would impact their firm than, perhaps, would be expected in response to less overarching events, such as moves made by competitors (Porac et al., 1989). It may be that some organizations, because of their history, the prior experiences of top management, or the information processing capacity of the top management team (Thompson and McDaniel, 1990) have more complex strategic frames with more linkages to performance issues. This complexity should increase the likelihood that a major event will be conceptually linked to performance and wellbeing. It may also be that frequent, though minor, changes in strategic behaviour enhance the complexity of strategic frames and make it more likely 
that new stimuli can be interpreted in terms of strategic action (Hedberg et al., 1976).

A second question raised by the study is related to the type of data we used to construct the maps. Clearly, the firms in our sample differ in the way in which they interpret the new legislation, especially the aspects of the legislation that are highlighted as onerous, or stressful. But it also is interesting to step back, and consider these differences in light of the data sources used. Since the source documents are speeches and annual reports designed to communicate with multiple audiences, diversity in response may also reflect this diversity in audience, or firm stakeholders. In other words, our finding that multiple indicators of pressure on the firm precedes action could be as much an effort to persuade multiple stakeholders of the need for change (or respond to multiple demands for change) as it is an indication of internal sensemaking alone. The observations are beyond the scope of the study, but well worth further investigation. Complicated conditions of sensemaking only add to our interest in the problem of timing, and underscore the potential significance of the patterns we found.

Finally, another interesting sensemaking complication lies in the observation that the slower responding firms may be learning from the faster responding firms. Because only the largest firms in the industry were selected for study, all the firms had the resources to wait and observe the experiences of others prior to forming their own strategies. Such an explanation for timing differences is consistent with the notion of industry recipes and industry influences proposed by Spender (1989) and Huff (1982), but it is not inconsistent with the premise that interpretation impacts the timing of response. It is certainly possible, in fact likely, that the 'borrowed experiences' (Huff, 1982) of faster responding firms might aid managers of the slower firms in forming their own interpretations, though there is no explicit reference to such influences in the data sources we used. Mimetic behaviour is of interest to institution theorists (e.g. DiMaggio and Powell, 1983), but we also need further enquiry into the conditions that encourage some firms to relate environmental change to their welfare without such examples.

\section{CONCLUSION}

Establishing the links between interpretation and action is frequently called for (Walsh, 1995) but only recently tackled by research on managerial and organization cognition. Previous research has suggested that the type of strategic change made by a firm is linked to managerial interpretation of the environment (Bateman and Zeithaml, 1989; Dutton and Jackson, 1987; Thomas et al., 1993). This study addresses the issue of the timing of strategic response to environmental change. Our results suggest that the timing of change involves more than just assigning meaning to a particular event. Consistent with work on individual cognition (Isabella, 1990), the results show that events that are not interpreted as affecting central concepts (performance or well-being) in the firm's strategic frame do not lead to a change in action. Further, change appears to be triggered by interpretations that link a given event to other concurrent or prior events, consistent with stress/inertia theories of change.

(C) Blackwell Publishers Ltd 1997 
Finally, it may appear that our analysis counters suggestions by Weick (1979), Starbuck and Milliken (1988) and others that managers act first and interpret their actions later. However, we suggest the results of this study point to an important middle ground between researchers who are interested in the purposeful, deliberate development of strategy and those who feel that strategy is more often an outcome of action. The changes in interpretation we identify here focus on an important interpretive step before change can take place: the realization that something needs to be done. Theories of institutional inertia and evolutionary theories of organization change we summarized provide needed insight into why this interpretive step is not taken without significant pressure to do so. Additional study of strategic frames and their relationship to the content of strategic response may provide a more clear picture of enactment processes, and poses an interesting avenue for future research. What our study suggests is that firms need a map in which they have confidence, before they undertake a major journey (Weick, 1990); they must 'know something' before they act. With this confidence, they then 'see what they do', and develop more detailed knowledge of new terrain in the way that Weick, Starbuck and others have been describing.

\section{NOTES}

*Presented at the 1992 Strategic Management Society Meeting, London, 14-17 October. This work draws significantly from the first author's dissertation. Support from the Richard D. Irwin Foundation, and the input of the dissertation committee is gratefully acknowledged.

[1] A fifth variable, R\&D emphasis on specific therapeutic categories of drugs, was also identified as a significant strategic variable. However, relevant firm-level information is not publicly available and therefore this dimension of strategy could not be investigated.

[2] All six companies were contacted about the availability of historical documents, but only two have promising repositories. To ensure equal level of documentation for each firm, documents from these two firms were not used in this analysis.

[3] The Kefauver bill referred to in this text is the original bill submitted to committee early in 1961. The two main provisions of this early version were compulsory licensing of new drugs after three years, and the requirement that new drugs be efficacious in use, as well as safe. This bill died in committee in 1962.

\section{REFERENCES}

Aluard Poesi, F. (1994). 'From individual causal maps to a collective causal map'. Second International Workshop on Managerial and Organizational Cognition Proceedings. Brussels, 26-27 May, 1-25.

Aluison, G. (1971). Essence of Decision. Boston: Little, Brown.

Anderson, C., Lepper, M. and Ross, L. (1980). 'Perseverance of social theories: the role of explanation in the persistence of discredited information'. Journal of Personality and Social Psychology, 39, 1037-49.

ANDREws, K. (1987). The Concept of Corporate Strategy. Homewood, IL: Irwin.

Axelrod, R. (1976). Structure of Decision. Princeton, NJ: Princeton University Press. 
Barnard, C. (1938). The Functions of the Executive. Cambridge, MA: Harvard University Press.

BarR, P., Stimpert, J. L. and Huff, A. (1992). 'Cognitive change, strategic action, and organizational renewal'. Strategic Management foumal, Summer Special Issue, 15-36.

BARTUNEK, J. (1984). 'Changing interpretive schemes and organizational restructuring: the example of a religious order'. Administrative Science Quarterly, 29, 355-72.

Bateman, T. and Zerthaml, C. (1989). 'The psychological context of strategic decisions: a model and convergent experimental findings'. Administrative Science Quarterly, 10, 59-74.

Bettman, J. and WeITZ, B. (1983). 'Attributions in the board room: causal reasoning in corporate annual reports'. Administrative Science Quarterly, 28, 165-83.

Bigelow, J. (1982). 'A catastrophe model of planned organizational change'. Behavioral Science, 27, 26-42.

BiRnbaum-More, P. H. and Weiss, A. R. (1990). 'Discovering the basis of competition in 12 industries: computerized content analysis of interview data from the US and Europe'. In Huff, A. S. (Ed.), Mapping Strategic Thought. Chichester: Wiley, 53-69.

Bougon, M., Weick, K. E. and BinkHorst, D. (1977). 'Cognition in organizations: analysis of the Utrecht Jazz Orchestra'. Administrative Science Quarterly, 22, 609-32.

Bowman, E. H. (1984). 'Content analysis of annual reports for corporate strategy and risk'. Interfaces, 14, 61-71.

Calori, R., Johnson, G. and Sarnin, P. (1994). 'CEO's cognitive maps and the scope of the organization'. Strategic Management foumal, 15, 437-57.

Cameron, K., Sutton, R. and Whetten, D. (1988). Readings in Organizational Decline. Cambridge, MA: Ballinger.

ChaKRAVARTHY, B. (1982). 'Adaptation: a promising metaphor for strategic management'. Academy of Management Review, 7, 33-44.

Clapham, S. and SchwenK, C. (1991). 'Self-serving attributions, managerial cognition, and company performance'. Strategic Management Joumal, 12, 219-29.

Cool, K. (1985). 'Strategic group formation and strategic group shifts: a longitudinal analysis of the US pharmaceutical industry, 1963-1982'. Unpublished doctoral dissertation, Purdue University, West LaFayette, Indiana.

Cyert, R. and March, J. (1963). A Behavioral Theory of the Firm. New Jersey: Prentice-Hall.

DAFT, R. and WEICK, K. (1984). 'Toward a model of organizations as interpretive systems'. Academy of Management Review, 9, 284-95.

Dimaggio, P. J. and Powell, W. W. (1983). 'The iron cage revisited: institutional isomorphism and collective rationality in organizational fields'. American Sociological Review, 48, 147-60.

Dutton, J. and Duncan, R. (1987). 'The creation of momentum for change through the process of strategic issue diagnosis'. Strategic Management Foumal, 8, 279-95.

DuTton, J. and JACKson, S. (1987). 'Categorizing strategic issues: links to organizational action'. Academy of Management Review, 12, 76-90.

Dutton, J., Fahey, L. and Narayanan, V. K. (1983). 'Toward understanding strategic issue diagnosis'. Strategic Management Joumal, 4, 307-24.

EDEN, C. (1990). 'Working on problems using cognitive mapping'. In Littlechild, S. C. and Shutler, M. (Eds), Operations Research in Management. London: Prentice-Hall.

EDEN, C. (1993). 'Strategy development and implementation: cognitive mapping for group support'. In Hendrix, J., Johnson, G. and Newton, J. (Eds), Strategic Thinking. Chichester: John Wiley.

Eden, C., Jones, S. and Sims, D. (1979). Thinking in Organizations. London: Macmillan.

Eden, C., Jones, S. and Sims, D. (1983). Messing about in Problems. Oxford: Pergamon.

Eden, C., Ackermann, F. and Tart, A. (1993). 'Comparing cognitive maps: methodological issues'. Paper presented at 1st International Workshop on Managerial and Organizational Cognition, Brussels. 
EHLINGER, S. (1994). 'How do centre's and peripheral units' cognitions interact during the strategic planning process?' Second International Workshop on Managerial and Organizational Cognition Proceedings, Brussels, 26-27 May, 151-78.

Evritt, B. (1980). Cluster Analysis, 2nd edn. London: Heinemann Educational.

Fahey, L. and Narayanan, V. K. (1989). 'Linking changes in revealed causal maps and environmental change: an empirical study'. Joumal of Management Studies, 26, 36178.

FIOL, M. (1989). 'A semiotic analysis of corporate language: organizational boundaries and joint venturing'. Administrative Science Quarterly, 34, 277-303.

Fiol, C. M. (1994). 'Consensus, diversity, and learning in organizations'. Organization Science, 5, 403-19.

Fiske, S. T. and TAYLOR, S. E. (1991). Social Cognition. New York: McGraw-Hill.

GIERE, R. (1988). Explaining Social Science: A Cognitive Approach. Chicago: The University of Chicago Press.

Gilbert, M. (1989). On Social Facts. Princeton, NJ: Princeton University Press.

GinsBerG, A. (1988). 'Measuring and modelling changes in strategy: theoretical foundations and empirical directions'. Strategic Management Joumal, 9, 559-75.

Ginsberg, A. and BuchHoltz, A. (1990). 'Converting to for-profit status: corporate responsiveness to radical change'. Academy of Management Joumal, 33, 445-77.

GrolA, D. and Sims, H. (1986). 'Social cognition in organizations'. In Sims, H. and Gioia, D. (Eds), The Thinking Organization. San Francisco: Jossey-Bass, 1-19.

Golden, B. (1992). 'The past is past - or is it? The use of retrospective accounts as indicators of past strategy'. Academy of Management Joumal, 35, 848-57.

Grabowski, H., Vernon, J. and Thomas, L. (1978). 'Estimating the effects of regulation on innovation: an internal comparative analysis of the pharmaceutical industry'. Joumal of Law and Economics, April, 133-63.

HaAs, P. M. (1992). 'Introduction: epistemic communities and international policy coordination'. International Organization, 46, 1-35.

HALL, R. (1984). 'The natural logic of management policy making: its implications for the survival of an organization'. Management Science, 30, 905-27.

Hambrick, D. (1984). 'Taxonomic approaches to studying strategy: some conceptual and methodological issues'. Fournal of Management, 10, 27-42.

HAMBrick, D. and D'AvenI, R. (1988). 'Large corporate failures as downward spirals'. Administrative Science Quarterly, 33, 1-23.

Hambrick, D. and Mason, P. (1984). 'Upper echelons: the organization as a reflection of its top managers'. Academy of Management Review, 9, 193-206.

Hannan, M. and Freeman, J. (1984). 'Structural inertia and organizational change'. American Sociological Review, 49, 149-64.

HARRIGAN, K. (1985). 'An application of clustering for strategic group analysis'. Strategic Management foumal, 6, 55-74.

Hartigan, J. A. (1976). Clustering Algorithms. New York: John Wiley.

Haveman, H. (1992). 'Between a rock and a hard place: organizational change and performance under conditions of fundamental environmental transformation'. Administrative Science Quarterly, 37, 48-75.

Hedberg, B., Nystrom, P. and Starbuck, W. (1976). 'Camping on seesaws: prescriptions for a self-designing organization'. Administrative Science Quarterly, 21, 41-65.

Hodgkinson, G. P. and Johnson, G. (1994). 'Exploring the mental models of competitive strategists'. Journal of Management Studies, 31, 525-49.

Hofer, C. and Schendel, D. (1978). Strategy Formulation: Analytical Concepts. St Paul, MN: West Publishing.

Holmes, T. and RaHe, R. (1967). 'The social readjustment rating scale'. Foumal of Psychosomatic Research, 11, 213-18. 
HuFF, A. S. (1982). 'Industry influences on strategy reformulation'. Strategic Management Joumal, 3, 119-31.

HuFf, A. S. (1990). 'Mapping strategic thought'. In Huff, A. S. (Ed.), Mapping Strategic Thought. Chichester: John Wiley, 11-49.

Huff, A. S., Narapareddy, V. and Fletcher, K. E. (1990). 'Coding the association of concepts'. In Huff, A. S. (Ed.), Mapping Strategic Thought. Chichester: John Wiley, 311-25.

Huff, J. O., Huff, A. S. and Thomas, H. (1992). 'Strategic renewal and the interaction of cumulative stress and inertia'. Strategic Management foumal, 13, 55-75.

IsABELLA, L. (1990). 'Evolving interpretations as a change unfolds: how managers construe key organizational events'. Academy of Management Joumal, 33, 7-41.

JenKINS, M. (1994). 'Creating and comparing strategic causal maps'. Second International Workshop on Managerial and Organizational Cognition Proceedings, Brussels, 26-27 May, 299328.

KeLly, G. (1955). The Psychology of Personal Constructs, Volumes 1 and 2. New York: Norton.

KIESLER, S. and Sproull, L. (1982). 'Managerial response to changing environments: perspectives on problem sensing from social cognition'. Administrative Science Quarterly, 27, 548-70.

KuHN, T. (1970). Structure of Scientific Revolutions, 2nd edn. Chicago: University of Chicago Press.

Lant, T., Miluiken, F. and Batra, B. (1992). 'The role of managerial learning and interpretation of strategic persistence and reorientation: an empirical exploration'. Strategic Management Joumal, 13, 585-608.

LASAGNA, L. and WARDELL, W. (1975). 'The rate of new drug discovery'. In Helms, R. (Ed.), Drug Development and Marketing. Washington DC: The American Institute for Public Policy Research.

LAUKKANEN, M. (1994). 'Comparative cause mapping of organizational cognitions'. Organization Science, 5, 322-43.

LAVE, J. and Wenger, E. (1991). Situated Leaming. Cambridge: Cambridge University Press.

LYLES, M. (1981). 'Formulating strategic problems: empirical analysis and model development'. Strategic Management Joumal, 2, 61-75.

LyLES, M. and MrTROFF, I. (1980). 'Organizational problem formulation: an empirical study'. Administrative Science Quarterly, 25, 102-19.

MARCH, J. (1991). 'Exploration and exploitation in organizational learning'. Organization Science, 2, 71-87.

March, J. and Simon, H. (1958). Organizations. New York: Wiley.

MARKoczy, L. and GoldBerg, J. (1995). 'A method for eliciting and comparing causal maps'. Journal of Management, 21, 305-33.

MEYER, A. (1982). 'Adapting to environmental jolts'. Administrative Science Quarterly, 27, 515-38.

Mires, R. (1982). Coffin Nails and Corporate Strategy. New Jersey: Prentice-Hall.

Mires, R. and Snow, C. (1978). Organizational Strategy, Structure, and Process. New York: McGraw-Hill.

MilleR, D. and Friesen, P. (1984). Organizations: A Quantum View. Englewood Cliffs, NJ: Prentice-Hall.

MILIKEN, F. (1987). 'Three types of uncertainty about the environment: state, effect, and response uncertainty'. Academy of Management Review, 12, 133-43.

MrLiken, F. (1990). 'Perceiving and interpreting environmental change'. Academy of Management Joumal, 33, 42-63.

MinsKY, M. (1975). 'A framework for representing knowledge'. In Winston, P. H. (Ed.), The Psychology of Computer Vision. New York: McGraw Hill. 
Mintzberg, H. (1978). 'Patterns in strategy formulation'. Management Science, 24, 934-48.

MinTZBERG, H. and WATERS, J. (1982). 'Tracking strategy in an entrepreneurial firm'. Academy of Management foumal, 25, 465-99.

MinTZBerg, H., RaisinghANI, D. and TheORET, A. (1976). 'The structure of unstructured decision processes'. Administrative Science Quarterly, 21, 246-75.

MonteVerde, K. and TeEce, D. (1982). 'Supplier switching costs and vertical integration in the automobile industry'. Bell Joumal of Economics, 207-13.

MYLlys, K. (1994). 'Cognitive approach to managerial work - an empirical study of Finnish bank managers in crisis situation'. Second International Workshop on Managerial and Organizational Cognition Proceedings. Brussels, 26-27 May, 419-44.

Narayanan, V. K. and Fahey, L. (1990). 'Evolution of revealed causal maps during decline: a case study of admiral'. In Huff, A. S. (Ed.), Mapping Strategic Thought. Chichester: John Wiley, 109-33.

Neisser, U. (1967). Cognitive Psychology. Englewood Cliffs, NJ: Prentice-Hall.

Nelson, R. R. and Winter, S. G. (1982). An Evolutionary Theory of Economic Change. Cambridge, MA: Cambridge University Press.

Nisbett, R. and Ross, L. (1980). Human Inference. Englewood Cliffs, NJ: Prentice-Hall.

Olivia, T. A., Day, D. L. and MacMillan, I. C. (1988). 'A generic model of competitive dynamics'. Academy of Management Review, 13, 374-89.

Oster, S. (1982). 'Intraindustry structure and the ease of strategic change'. Review of Economics and Statistics, 64, 376-83.

Porac, J., Thomas, H. and Baden-Fuller, C. (1989). 'Competitive groups as cognitive communities: the case of Scottish knitwear manufacturers'. Joumal of Management Studies, 26, 397-416.

Porter, M. (1980). Competitive Strategy. New York: Free Press.

Powell, W. and Dimaggio, P. (1991). The New Institutionalism in Organization Analysis. Chicago: University of Chicago Press.

Prahalad, K. and Bettis, R. (1986). 'The dominant logic: a new linkage between diversity and performance'. Strategic Management Fournal, 7, 485-501.

QuINN, J. (1980). Strategies of Change, Logical Incrementalism. Homewood, IL: Irwin.

REgER, R. and Huff, A. (1993). 'Strategic groups: a cognitive perspective'. Strategic Management foumal, 14, 103-24.

Robinson, W. (1957). 'The statistical measure of agreement'. American Sociological Review, 22, 17-25.

Ross, L., Lepper, M. and HubBard, M. (1975). 'Perseverance in self-perception and social perception'. Fournal of Personality and Social Psychology, 32, 880-92.

RuMELhaRT, D. (1980). 'Schemata: the building blocks of cognition'. In Spiro, Bruce and Brewer (Eds), Theoretical Issues in Reading Comprehension. Hillsdale, NJ: Erlbaum, 33-58.

SalanciK, G. and MeINDL, J. (1984). 'Corporate attributions as strategic illusions of management control'. Administrative Science Quarterly, 29, 238-54.

SAS Instrtute, Inc. (1990). SAS Users Guide: Basics, Version 6, 4th edn. Chapter 6, 53101.

ScHeID-Cook, T. (1992). 'Organizational enactments and conformity to environmental prescriptions'. Human Relations, 45, 537-54.

SchWENK, C. and TANG, M. (1989). 'Economic and psychological explanations for persistance'. Omega, 17, 559-70.

Selznick, P. (1957). Leadership in Administration. Evanston, IL: Row, Peterson.

Shrivastava, P. and LiN, G. (1984). 'Alternative approaches to strategic analysis of environments'. Paper presented at the 4th Annual Strategic Management Society Conference, Philadelphia.

SMTTH, K. and GRIMM, C. (1987). 'Environmental variation, strategic change, and firm performance: a study of railroad deregulation'. Strategic Management Joumal, 8, 363-76. 
SPEnder, J. C. (1989). Industry Recipes: An Inquiry into the Nature and Sources of Managerial Fudgement. Cambridge, MA: Basil-Blackwood, Inc.

StarbucK, W. and Milliken, F. (1988). 'Executives perceptual filters: what they notice and how they make sense'. In Hambrick, D. (Ed.), The Executive Effect: Concepts and Methods for Studying Top Managers. Greenwich, CT: JAI.

StJernberg, T. and Ullistad, C. (1994). 'Organization images - organizational diagnosis by transformation of individuals' cognitive maps into shared local theories'. Second International Workshop on Managerial and Organizational Cognition Proceedings, Brussels, 26-27 May, 601-22.

Temin, P. (1980). Taking Your Medicine: Drug Regulation in the United States. Cambridge, MA: Harvard University Press.

Thomas, J., Clark, S. and Grola, D. (1993). 'Strategic sensemaking and organizational performance: linkages among scanning, interpretation, action, and outcomes'. Academy of Management Joumal, 36, 239-70.

Thompson, J. (1967). Organizations in Action. New York: McGraw-Hill.

THOMPson, J. and McDANIEL, R. (1990). 'Interpreting strategic issues: effects of strategy and the information-processing structure of top management teams'. Academy of Management Joumal, 33, 286-306.

Tushman, M. and Romanelli, E. (1985). 'Organizational evolution: a metamorphosis model of convergence and reorientation'. Research in Organizational Behavior, 7, 171-222.

WALSH, J. (1995). 'Managerial and organizational cognition: notes from a trip down memory lane'. Organization Science, 6, 280-321.

WARDELL, W. (1971). 'Introduction of new therapeutic drugs in the US and Great Britain: an international comparison'. Clinical Pharmacology and Therapeutics, 14, 773-90.

WeIcK, K. (1979). The Social Psychology of Organizing. Reading, MA: Addison-Wesley.

WeICK, K. (1990). 'Cartographic myths in organizations'. In Huff, A. S. (Ed.), Mapping Strategic Thought. Chichester: John Wiley, 1-10.

WeICK, K. and BougON, M. (1986). 'Organizations as cognitive maps: charting ways to success and failure'. In Gioia, D. and Sims, Henry Jr. (Eds), The Thinking Organization. San Francisco: Jossey-Bass.

Wood, M. (1996). 'Situating cognition: organizations as communities-of-practice'. 4th International Workshop on Managerial and Organizational Cognition Proceedings, Stockholm, 2930 August, 1996.

WoODrum, E. (1984). 'Mainstreaming content analysis in social science - methodological advantages, obstacles, solutions'. Social Science Research, 13, 1-9.

ZajaC, E. and ShORTELL, S. (1989). 'Changing generic strategies: likelihood, direction, and performance implications'. Strategic Management foumal, 10, 413-30. 
Copyright of Journal of Management Studies is the property of Blackwell Publishing Limited and its content may not be copied or emailed to multiple sites or posted to a listserv without the copyright holder's express written permission. However, users may print, download, or email articles for individual use. 